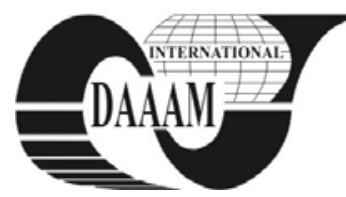

\title{
THE INFLUENCE OF INTERCRITIC QUENCHING IN ULTRASONIC FIELD ON THE MECHANICAL PROPERTIES OF A DUAL-PHASE STEEL DETERMINED BY UNIVERSAL HARDNESS TEST
}

\author{
DULUCHEANU, C[onstantin]; SEVERIN, T[raian] - L[ucian] \& BANCESCU, N[icolai]
}

\begin{abstract}
In this article, the authors present the cooling influence in ultrasonic field on the mechanical properties of a dual-phase steel with $0.09 \% \mathrm{C}$ and $1.90 \% \mathrm{Mn}$ obtained by intercritical quenching. The heat treatment consisted of heating to $740^{\circ} \mathrm{C}$, maintaining for 30 minutes and then cooling in water and water in ultrasonic field. Mechanical properties have been highlighted through universal hardness testing; were determined: Martens hardness (HM), Martens hardness from the slope of the increasing force/indentation depth curve $\left(H M_{S}\right)$, indentation hardness $\left(H_{I T}\right)$, elastic indentation modulus $\left(E_{I T}\right)$, indentation creep $\left(C_{I T}\right)$, elastic $\left(\eta_{I T}\right)$ and plastic $\left(\eta_{\text {plast }}\right)$ parts of the indentation work.
\end{abstract}

Key words: dual-phase steel, universal hardness, creep, tester

\section{INTRODUCTION}

Dual-phase steels are alloys with low carbon content and a structure consisting of a soft and tough ferrite matrix ( $75 \div 85 \%)$ in which one can find homogeneously dispersed martensite and a small amount of residual austenite and lower bainite. In these materials stress-strain curve is continuous without yield; their work hardening is very fast at small stress, have low yield strength and a high tensile strength (very small $\mathrm{R}_{\mathrm{p} 0,2} / \mathrm{R}_{\mathrm{m}}$ ratio). The superiority of dual-phase steels, in comparison with other steels, is determined not only by their great strength and plasticity, but mostly by the possibility of obtaining a high combination of these properties. The main method of producing dual-phase steels consisted in quenching at temperatures in the range $(\alpha+\gamma)$; the structure obtained by intercritical heat treatment is the result of combined action of heating temperature and cooling rate. The influence of these two technological parameters on the microstructure of the material is directly reflected on the properties of the dual-phase steel (Rashid, 1981) (Dulucheanu, 1999). Interest for using ultrasonic in heat treatments practice is new, being studied especially their influence on the cooling capacity of mediums to quenching steel. Experiments have shown that applying an ultrasonic field on fluid cooling increases the cooling capacity of the physico-chemical mediums, while eliminating one of the most dangerous stages of cooling, namely calefaction. (Bancescu \& Dulucheanu, 2001).

\section{EXPERIMENTAL DETAILS}

The research has been conducted on a steel whose chemical composition is shown in Table 1.

\begin{tabular}{|c|c|c|c|c|c|c|c|c|c|c|}
\hline \multirow{2}{*}{$\begin{array}{c}\text { Steel } \\
\text { symbol }\end{array}$} & \multicolumn{10}{|c|}{ Chemical composition, [\%] } \\
\cline { 2 - 9 } & $\mathrm{C}$ & $\mathrm{Mn}$ & $\mathrm{Si}$ & $\mathrm{Cr}$ & $\mathrm{Ni}$ & $\mathrm{Mo}$ & $\mathrm{Al}$ & $\mathrm{Cu}$ & $\mathrm{P}$ & $\mathrm{S}$ \\
\hline$D P S$ & 0.09 & 1.90 & 0.06 & 0.10 & 0.09 & 0.03 & 0.012 & 0.15 & 0.019 & 0.011 \\
\hline
\end{tabular}

Tab. 1. The chemical composition of material

The ferrite-martensite structure has been obtained by quenching from temperature in the range $(\alpha+\gamma)$; heating temperature $\left(\mathrm{T}_{\mathrm{Q}}\right)$ was selected to $740{ }^{\circ} \mathrm{C}$, value dictated by the position of the critical point $A_{c_{1}}$ and potential adjustment of thermal plants used; the time for maintaining at the heating temperature $\left(\mathrm{t}_{\mathrm{m}}\right)$ was established at 30 minutes. The heating to temperatures of heat treatment was performed in a electrical furnace for laboratory to $6 \mathrm{~kW}$, powered with a voltage of 380 $\mathrm{V}$. The cooling from intercritic range $(\alpha+\gamma)$ was achieved in two mediums: water (W) and water in the ultrasonic field (WUS). The plant of quenching in a ultrasonic field containing a tank of $20 \mathrm{dm}^{3}$ capacity (made of stainless steel) and an ultrasonic generator which provides a power output of $200 \mathrm{~W}$ and a frequency between 20 and $60 \mathrm{kHz}$; for these research operating frequency was $40.4 \mathrm{kHz}$ (Table 2).

\begin{tabular}{|c|c|c|c|}
\hline \multirow{2}{*}{ Code } & \multicolumn{3}{|c|}{ Technological parameters of intercritical quenching } \\
\cline { 2 - 4 } & $\begin{array}{c}\mathrm{T}_{\mathrm{Q}} \\
{\left[{ }^{\circ} \mathrm{C}\right]}\end{array}$ & $\begin{array}{c}\mathrm{t}_{\mathrm{Q}} \\
{[\mathrm{min}]}\end{array}$ & Quenching medium \\
\hline $\mathrm{Q}_{\mathrm{W}}$ & 740 & 30 & W: Water $\left(\mathrm{T}_{\mathrm{W}}=20^{\circ} \mathrm{C}\right)$ \\
\hline $\mathrm{Q}_{\text {wUS }}$ & 740 & 30 & $\begin{array}{c}\text { WUS: Water in ultrasonic field; } \\
\left(\mathrm{f}=40.4 \mathrm{KHz}, \mathrm{I}=2 \mathrm{~W} / \mathrm{dm}^{2}, \mathrm{~T}_{\mathrm{W}}=20^{\circ} \mathrm{C}\right)\end{array}$ \\
\hline
\end{tabular}

Tab. 2. Variations of intercritical quenching technology

The research was conducted with the material presented in table 1 (DPS), cylindrical samples $(\phi 10 \times 15)$ that were subject to two types of intercritic quenching; have made three sets of samples for each variant of heat treatment, each set with five samples. Heat treatments applied to DPS steel led to obtaining ferrite-martensite structure which fall within the definition of dual-phase steel literature $(24 \div 25 \%$ volume fraction of martensite).

After intercritic quenching, samples were tested for universal hardness on a SHIMATZU dynamic ultra-micro hardness tester DUH-211S. In this test, specific deformation sizes was determining under load. In the case of the conventional hardness test, hardness is calculate used the plastic component of strain and the universal hardness is used for both component deformation, plastic and elastic deformation component. The principle of universal hardness test consists in a progressively increasing load of indenter on the material tested, along with continuous measurements of pairs of values force/indentation depth. After reaching a prescribed indentation forces start unloading at the same speed as the load, resulting in a loading-unloading curve. This system of loading and unloading indentation reading and memorizing pairs of values force/indentation depth gives the possibility to determine not only the universal hardness, but also some important indices of the material (elastic modulus, strain hardenability, tendency to creep, plastic deformation work etc.) characteristics for which a separate determination is required significant logistical and an extraordinarily long time (Gutt et.al., 2000; ***, 2002).

All experiments and measurements were made at "Stefan cel Mare" University of Suceava, Romania, in laboratories of the Faculty of Mechanical Engineering, Mechatronics and Management and the Faculty of Food Engineering. 


\section{RESULTS AND DISCUSSION}

Each dual-phase steel sample was subjected to 5 universal hardness testing, for each test, realizing graphical development value pairs force/indentation depth in the process of loading and unloading (fig. 1.). Loading force at $500 \mathrm{mN}$ was applied in a progressively increasing in 15 seconds; following indices were determined: Martens hardness (HM), Martens hardness from the slope of the increasing force/indentation depth curve $\left(\mathrm{HM}_{\mathrm{S}}\right)$, indentation hardness $\left(\mathrm{H}_{\mathrm{IT}}\right)$, elastic intentation modulus $\left(E_{I T}\right)$, indentation creep $\left(\mathrm{C}_{\mathrm{IT}}\right)$, elastic $\left(\eta_{\mathrm{IT}}\right)$ and plastic $\left(\eta_{\text {plast }}\right)$ parts of the indentation work.

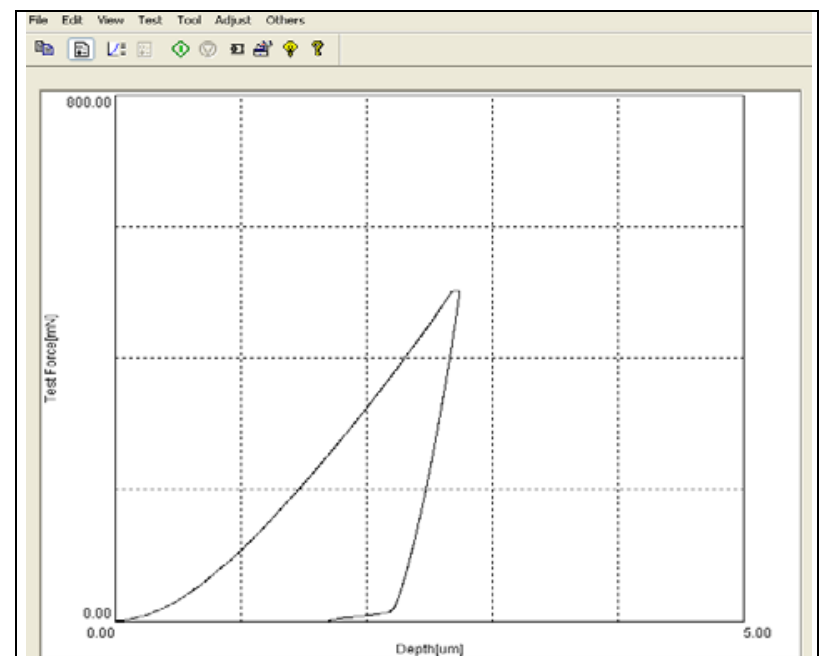

Fig. 1. Graphical representation of the evolution of pairs values force/indentation depth for a sample quenching in ultrasonic field

The results from experimental data are presented in table 3 and figures $2 \div 3$.

\begin{tabular}{|c|c|c|c|c|c|c|c|}
\hline $\begin{array}{c}\text { Heat } \\
\text { treatment }\end{array}$ & $\left.\left.\begin{array}{c}\mathrm{HM} \\
{\left[\mathrm{N} / \mathrm{mm}^{2}\right]}\end{array}\right] \begin{array}{c}\mathrm{HM}_{\mathrm{s}} \\
{\left[\mathrm{N} / \mathrm{mm}^{2}\right]}\end{array}\right] \begin{array}{c}\mathrm{H}_{\text {IT }} \\
{\left[\mathrm{N} / \mathrm{mm}^{2}\right]}\end{array}$ & $\begin{array}{c}\mathrm{E}_{\text {IT }} \\
{\left[\mathrm{N} / \mathrm{mm}^{2}\right]}\end{array}$ & $\begin{array}{c}\mathrm{C}_{\mathrm{IT}} \\
{[\%]}\end{array}$ & $\begin{array}{c}\eta_{\mathrm{IT}} \\
{[\%]}\end{array}$ & $\begin{array}{c}\eta_{\text {plast }} \\
{[\%]}\end{array}$ \\
\hline $\mathrm{Q}_{\mathrm{W}}$ & 2218 & 1658 & 3070 & $8.60 \cdot 10^{4}$ & 1.71 & 23.3 & 76.7 \\
\hline $\mathrm{Q}_{\text {wus }}$ & 2305 & 1875 & 3221 & $8.91 \cdot 10^{4}$ & 1.61 & 24.9 & 75.1 \\
\hline
\end{tabular}

Tab. 3. Experimental results

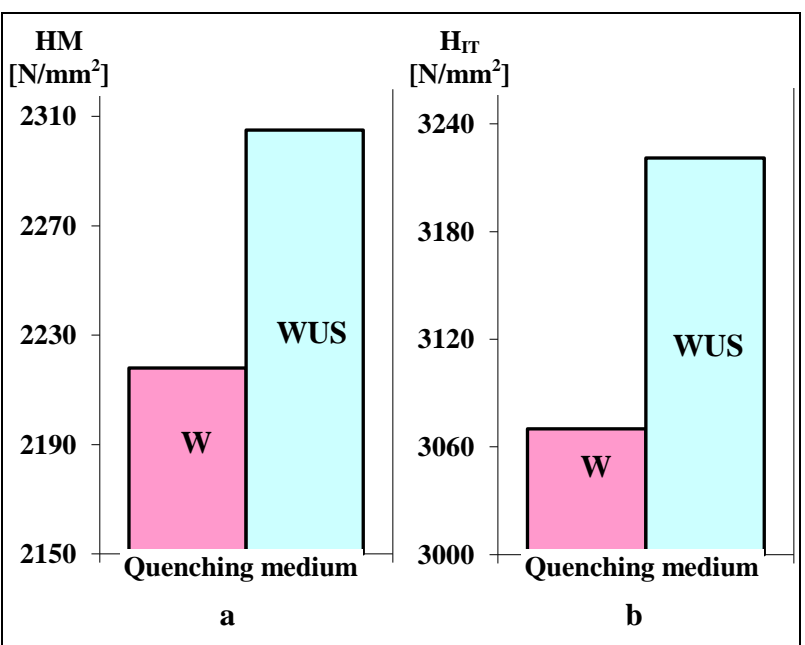

Fig. 2. The influence of quenching medium on the Martens hardness - HM (a) and the intentation hardness - $\mathrm{H}_{\mathrm{IT}}$ (b)

Analyzing the results is observed that cooling water in ultrasonic field increased the hardness of about $4 \div 5 \%$ beside the quenching in water (for example, from $2218 \mathrm{~N} / \mathrm{mm}^{2}$ to 3221 $\mathrm{N} / \mathrm{mm}^{2}$ for $\mathrm{HM}$ and from $3070 \mathrm{~N} / \mathrm{mm}^{2}$ to $3221 \mathrm{~N} / \mathrm{mm}^{2}$ for $\mathrm{H}_{\mathrm{IT}}$ ), these results together with those obtained for elastic indentation modulus $\left(\mathrm{E}_{\mathrm{IT}}\right)$, indentation creep $\left(\mathrm{C}_{\mathrm{IT}}\right)$ and elastic $\left(\eta_{\mathrm{IT}}\right)$ and plastic $\left(\eta_{\mathrm{IT}}\right)$ parts of the indentation work function indicates that increased values of hardness, so the strength properties, there was a decrease in the plasticity/toughness. Unfortunately, increasing strength properties lead to higher values of the ratio $\mathrm{R}_{\mathrm{p} 0,2} / \mathrm{R}_{\mathrm{m}}$, ratio what represents an important characteristic of dual-phase steel.

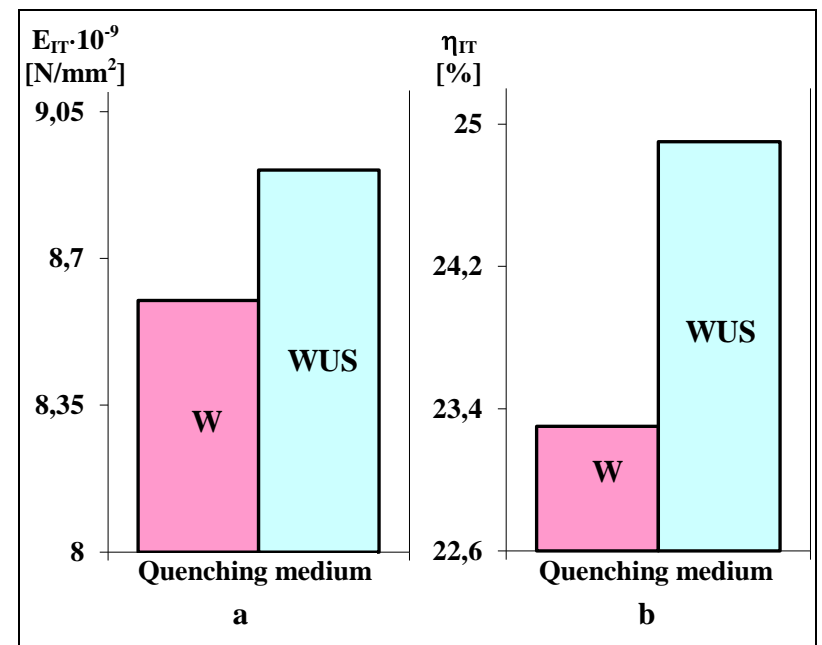

Fig. 3. The influence of quenching medium on the elastic intentation modulus - $\mathrm{E}_{\mathrm{IT}}$ (a) and the elastic part of the intentation work - $\eta_{\text {IT }}$ (b)

\section{CONCLUSIONS}

- Universal hardness test is a relatively new method of testing materials that can be measured easily and quickly, a series of material indices for which a separate determination is required significant logistical and extraordinarily long time.

- The two quenching mediums used in this research, water (W) and water in the ultrasonic field (WUS) were able to obtaining ferrite-martensite structures, which fell within the definition of dual-phase steel literature.

- Mechanical properties determined following universal hardness tests performed on dual-phase steel samples with $0.09 \% \mathrm{C}$ and $1.90 \% \mathrm{Mn}$ showed that quenching in ultrasonic field led to a slight increase in strength characteristics and low plasticity decrease, with negative influence on the value ratio $\mathrm{R}_{\mathrm{p} 0,2} / \mathrm{R}_{\mathrm{m}}$, ratio witch for dual-phase steel is an important indicator of the deformation capacity.

\section{ACKNOWLEDGEMENTS}

In this way, we thank Professor Georg Gutt from "Stefan cel Mare" University of Suceava, Romania, for advice, guidance and support.

\section{REFERENCES}

Bancescu, N. \& Dulucheanu, C. (2001), Research on the Usage of New Quenching Mediums in Heat Treatments, Buletinul Institutului Politehnic din Iasi, Tomul XLVII (LI), Fasc. 1 -2 , page $103-106$, ISSN $1453-1690$

Dulucheanu, C. (1999), Contributions on the Physical, Mechanical and Technological Properties of the FerriteMartensite Dual-Phase Steels, PhD Thesis, "Dunarea de Jos" University of Galaţi, Romania

Gutt, G., Palade D. D., Gutt S., Klein, F., \& Schmitt - Thomas K. G., (2000). Testing and Characterization of the Metallic Materials, Ed. Tehnica, Bucuresti, ISBN 973-31-1574-6

Rashid, M.S. (1981), Dual-Phase Steels, Ann. Rev. Mater. Sci., 11 , page $245-266$

$* * *(2002)$, ISO 14577-1:2002 (E) 